\title{
Research on Operation Control Strategy of DC Micro Grid
}

\author{
Yunlin Guan \\ Jinzhou Power Supply Branch \\ State Grid Liaoning Electric Power Supply Co. Ltd \\ Jinzhou, China \\ e-mail: guanyljz@163.com
}

\author{
Yang Zhao \\ Jinzhou Power Supply Branch \\ State Grid Liaoning Electric Power Supply Co. Ltd \\ Jinzhou, China \\ e-mail: zhaoyjz@163.com
}

\begin{abstract}
With the development of society, the energy and environmental problems have emerged, and restricts the development of traditional large power grid. In such a situation, it is particularly important for the rational use of new and renewable energy, so the power supply form of distributed generation has been paid more and more attention. Distributed power advantage lies not only in its renewable and environmental effect, electric energy can also be local consumption of its formation, save the transmission cost. But the limitations of distributed power itself, such as its fluctuation, poor controllability, and single access costs are higher, which restrict the development of. Micro grid concept then in Shangdi mostly solves all problems in distributed power grid access; provide more development space for distributed energy resources. This paper studies the DC micro grid, less research at the present stage of its, but because of its relative to the traditional AC micro grid in transmission and distribution from various advantages, I believe there will be a great space for development.
\end{abstract}

Keywords- power grid; renewable; effect; concept; advantages

\section{INTRODUCTION}

Distributed generation is usually refers to the small module for thousands of watts to hundreds of MW, decentralized, arrangement of power generation in the user in the vicinity of the efficient, reliable power unit [1]. Mainly includes: a liquid or gas as the fuel of internal combustion engine, micro gas turbine, solar power (photovoltaic, photo thermal power generation), wind power, biomass power generation. Has been as effective supplement of large power grid, distributed generation with the development of its own technology and grid connection technology, the power supply of this new form has received more and more attention.

Such as distributed power photovoltaic generation, wind power generation using natural non fossil energy, compared with the traditional centralized power generation has obvious advantages: the abundant energy, renewable, for less environmental pollution, simple equipment, flexible operation, use the send and the characteristic that use, not only can reduce the power loss of a large number of the transport process, the operation and maintenance costs compared with the traditional centralized power also will greatly reduce the $[2,3]$. As the important support and supplement with large capacity and long distance features of large power grid, distributed power supply can also many ways for large power grid to help, such as: avoid grid capacity is too large, help power grid peak, improve power system reliability. In recent years, the research and Application about distributed generation has many countries were put on the plan, and accompanied by the construction of a large amount of distributed generation projects, with enormous potential benefits of distributed energy is constantly developed and distributed generation will undoubtedly become one of the development trend of power system.

Although the distributed power supply has many advantages mentioned above, but the disadvantages are also obvious, it has the random fluctuation, poor controllability, computer access cost, if too many connected to the power system, will to power system and control the quality of power supply caused negative effects In 2001 the United States issued a used to limit excessive access large distributed generation grid number "IEEE_P1547/D08" of the draft, the provisions: once the large power grid failures, we must first time cutting all ties between distributed generation and grid. In order to adjust the conflict between the large power grid and distributed generation, the distributed generation within their abilities as much as possible to be developed more utility, and accompanied by the development of the power electronic interface technology and modern control theory, the countries of the world through the study of constant exploration and then puts forward the concept of micro grid.

Micro grid is defined by the distributed power, energy storage device, the energy conversion device, load and the monitoring and protection device from a small power supply system. Micro power supply for many distributed power supply capacity of small, small unit that contains the power electronic interface, can device comprises a micro gas turbine, fuel cells, photovoltaic cells, small wind turbines and super capacitors, flywheel battery storage and etc.. They meet at the user side, has the advantages of low cost, low voltage and small pollution characteristics.

The biggest difference between the micro grid and traditional power system is composed of structure, micro grid can be more free to change according to the needs and conditions. At present there exist three kinds of forms of the micro grid, i.e. AC micro grid, DC micro grid and $\mathrm{AC} /$ $\mathrm{DC}$ hybrid micro grid. Among them, for the traditional AC micro grid micro grid structure, AC / DC hybrid micro grid features the most comprehensive, and the structure is most complex, the study on DC hybrid micro grid and the turn 
of the micro grid are relatively new and has great development prospects.

With the development of society, network scale is continually expanding, and the disadvantages of large scale power grid is also increasingly highlighted: the operation is complex and difficult, high running maintenance cost for users, more and more high electric safety and reliability requirements and power supply to meet the diversified demands of the difficult. In recent years, several large-scale blackouts worldwide have attracted more and more people think the disadvantages for large power grid. In order to solve the problems of large power grids, the world will also study the focus of more and more biased in favor of micro grid, so there is no doubt that the stage of micro grid in the power system in the future will become more and more broad.

The current research on Micro grid Chinese is still in the initial stage, the developed countries are now in accordance with their own national conditions suitable for micro grid concept put forward their own, our country for the micro grid has not put forward clearly defined. Although China's pace of development of micro grid is still relatively slow, but based on China vast land area, the diverse conditions, the micro grid in our country has a great space for development.

In recent years, the Chinese Academy of Sciences and the enterprises and institutions of higher learning are also actively to carry out a research of micro grid. At present our country micro grid research although with the international advanced level there is still a considerable gap, but also has made some progress, if you want to reach the world advanced level in the research of micro grid, there is a long way to go.

\section{DC MICRO GRID OVERVIEW}

\section{A. DC micro grid concept}

DC micro grid basic structure show in Fig 1. In this structure, assuming no loss of DC bus, micro electric network through the main circuit breaker and the bidirectional synchronization switch corresponding with large grid connected, two kinds of operation mode to achieve grid connected and islanded. Distributed power supply in the micro grid can be divided into two categories: one is the DC micro power, such as photovoltaic cells, fuel cells, batteries and so on; the other is a micro power exchange, such as micro gas turbine and wind power generator. In the DC micro grid, the distributed power through power electronic equipment must be as converter and DC bus is connected, and the power is allocated to the load side via DC bus. The corresponding DC/DC equipment and $\mathrm{DC} / \mathrm{AC}$ equipment will be used to meet the different requirements for different load voltage grade.

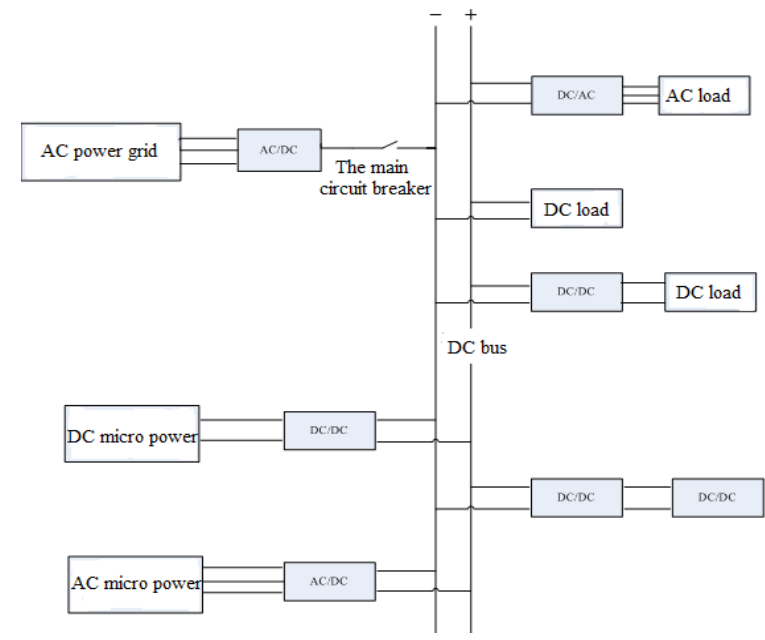

Figure 1. The typical structure of DC micro grid

\section{B. The advantages and disadvantages of DC micro grid}

Outside DC micro grid except have prior to the micro grid has the advantages, compared with the traditional AC micro grid; it also has the following advantages:

(a) In the DC micro grid system, because it does not need to consider the AC output voltage of power supply phase, frequency and other issues, the connection between the form of distributed power supply and DC bus will be more simple, convenient, and often only one $\mathrm{AC} / \mathrm{DC}$ or $\mathrm{DC} / \mathrm{DC}$ transform. The DC bus is just one of four quadrant operation switch through the realization of grid connected operation and large power grid. The structure characteristics of DC micro grid will also greatly reduce the system cost and loss.

(b) Control of DC micro grid considering only the DC bus voltage, power flow control to a greater extent depends on the current, so the more easily for the coordinated control of the distributed power supply.

(c) Compared to the traditional AC micro grid, DC micro grid in commutation device is simplified a lot, so it is more beneficial to reduce the system cost and loss.

(d) Now DC equipment increasing, if the DC micro grid directly into the distribution system, can be direct solar electricity generated direct supply DC equipment, power utilization will be more effective then produced by solar energy.

Although micro grid with $\mathrm{DC}$ by $\mathrm{AC}$ has many advantages compared with the above mentioned, but it also has its disadvantages. First of all, design standard application of DC in the micro grid has not yet unified and standardized; secondly, the DC is common but zero, so the DC micro grid has arc difficult this all dc. In addition, the micro grid in the distributed power equivalent to a voltage source, the parallel may produce circulation together.

\section{DC micro grid operation control}

There are mainly two kinds of operation mode of micro grid: grid connected and islanded operation. Different modes of operation will use the corresponding control strategy to realize the control requirements.

Islanding mode refers to the micro grid from large AC power grid run separately, only distributed power sources such as photovoltaic power generation systems, power 
generation systems, wind turbine energy storage device for load power supply, this mode of operation requires energy and load distributed power emitted energy absorbed do real-time matching. However, distributed power supply has great uncertainty and randomness, such as the output capacity of photovoltaic power generation system affected by light and temperature significantly, when it is cloudy or suddenly the clouds passing ability, its output will decline sharply; power generated by wind speed fan operation directly determines, when the wind suddenly big suddenly small is not stable, the output power will dramatically change; battery although it can stabilize the output, but because of its limited capacity cannot long time power supply, so also has its uncertainty. So if the island operation mode of micro grid design corresponding control strategy, the key lies in the real-time acquisition of the load side demand, and to achieve distributed power output and real time, and the load grade, in the islanded system to satisfy all meet the demand when cutting off the main match.

Grid connected operation mode refers to the micro grid by grid switch access AC large power grid and run with them. Compared with the micro grid, AC power grid capacity can be regarded as infinite. Therefore, in the micro grid operation, no need to consider whether the output distributed power supply to meet the load demand side, energy storage device does not work in the charging is completed, for the control of the DC bus voltage is mainly by adjusting the connection between the micro grid and AC large power grid and network switch to achieve, only in the distributed power supply is greater than load demand side and the system does not allow the micro grid into a large power grid feedback power only by adjusting the distributed power output voltage to maintain the bus voltage stability. Typically, as long as the grid allows the micro grid to the feedback electric energy, distributed power are generally in accordance with the maximum power output can reach to the grid in real-time, feedback energy and sell electricity to obtain economic benefits; and when the large $\mathrm{AC}$ grid does not allow the micro grid to the feedback power situation, for the control of micro power will be depending on the circumstances, when the load is large distributed power working in the maximum power output mode, when the load is small, distributed power need to undertake the DC bus voltage stability of task and work in a regulated output mode.

\section{MOTION CONTROL STRATEGY STRUCTURE DESIGN}

\section{A. Feedback control switch}

A large number of access of distributed generation in micro grid, will produce very big change radiation type power supply mode for medium and low voltage distribution networks traditionally used most often, but by a single power supply to distribute the power mode is changed to the multi power supply mode, may make the power system and management of distributed power supply can be controlled, and caused a lot of problems in the corresponding power system security and stability, concrete can be divided into the following four points:

(A) Compared with the large power grids, micro grid capacity is relatively small, so micro grid usually adopts the voltage grade is relatively low in grid connected. When the short circuit fault, micro grid will choose from a network into islanded operation mode, but not on the grid to form an effective support, so in the micro grid and large power grid power transmission due to mutual power grid fault suddenly cut off and large power grid connection, micro grid will appear power shortage or excess load power, may even burn out the micro grid collapse.

(B)In the low voltage level of the power grid, usually adopts three section current protections as measures of protection relay. So when the micro grid with low voltage level grid, will make the micro relay and large power grid protection setting coordination complex.

(C)The distributed power supply a large number of small capacity of access grid system, will make the most of the main transformer neutral point $110 \mathrm{Kv}$ in power grid operation directly grounded, cause the system short circuit to ground capacitance increase greatly, which makes the single-phase grounding fault current is even higher than the three-phase short-circuit current, the complexity is increased system of relay protection work.

(D)Because of the distributed power supply uncertainty, if a large number of access network will increase the complexity of grid scheduling, operation, information acquisition, real-time monitoring of the process. Thermal power plant and the need for micro grid left margin, in distributed power to the network side a lot of feedback power also need adjust the output of power plant, so that the grid scheduling complex.

\section{B. The natural condition analysis layer}

In this paper the hierarchical control structure, effects of natural condition analysis layer is a collection of light intensity, temperature, wind speed, load and other parameters.

(A) The light intensity changes decided to photovoltaic power natural conditions for the temperature and light intensity, and temperature under normal circumstances not mutation, so the authenticity of simulation environment based on the natural conditions, the subject in the analysis layer is designed in the light intensity variation module, by changing the light intensity to change the output of photovoltaic module.

The light intensity is an important factor to decide the output of photovoltaic power generation system, but as the days of the ominous clouds, changes in the weather situation is most complex, because the clouds covers the light intensity can have very large fluctuations, so the randomness of photovoltaic power generation system for very large. In the micro grid, photovoltaic power generation is one of the most important sources of power, through the light photovoltaic intensity caused by the fluctuation of output fluctuations as a micro grid system disturbances, will be more conducive to the stability analysis of the system, confirmed the validity of the control strategy.

(B) A big advantage of DC micro grid access change the actual load distribution system is directly supply DC load without the converter rectifier, which will greatly decrease the power loss of converter, so the DC micro grid model building will be equipped with the DC load.

In the micro grid reality, load supply must always in constant change, which requires the controller of micro grid power real-time coordination of various distributed 
power supply with the change of load matching, maintain the stability of micro grid. And in the verification of various micro grid stability disturbances, with large load fluctuation is as more representative disturbance, more convincing for verifying the effectiveness of the control strategy for stabilizing purposes.

(C) The actual wind speed change as one of the important distributed power in micro grid, power output of wind power generator is mainly decided by the wind. For the average wind power generator, and cut-out wind speed there is a cut in wind speed, minimum speed that allows the cut in wind speed wind generator, the maximum wind speed cut-out wind speed which allows the wind generator, namely the external natural wind in the cut in and cut-out wind speed between, wind generators allowed to work, and in the wind speed range memory in a critical wind speed, for direct drive permanent magnet type fan of this subject, between a cut in wind speed and the critical wind speed of the fan and the wind power is proportional to the change in the critical wind speed, fixed rate and cut-out wind speed wind turbine output power, does not increase with the increase in wind speed.

The nature of the velocity is changing, but not like the wind speed above the light intensity that have greater mutation an instantaneous, but due to the inertia effect of the fan blade, the influence of wind velocity on the fan power is relatively slow.

\section{The control decision-making layer}

Control decision layer effect of feedback control switch and the natural conditions for the comprehensive collection layer of information grid, after analysis were chosen to control and operation of photovoltaic power generation system and the fan in the power system, making the whole micro grid can adapt to various situations of the integrated control strategy.

\section{Operation layer}

Hierarchical control structure of the last layer, the control unit control layer and a photovoltaic module, wind generator module is directly connected, the final choice to participate in the distributed power supply module operation mode. Parameters for each module specific control system under various operating modes of operation layer is arranged inside the stored well, running in the system, the operation of the receiving control mode selection signal to a control decision layer sends, control of each module operates in accordance with the fixed control policy.

\section{CONCLUSION}

In the DC power system, DC micro grid is a distributed power supply and load and storage of renewable energy device combining way. The alternating current can form the main body status, load and power supply circuit is designed according to the existing AC power production, but once the DC power supply mode of small scale, has been applied in real life, so with the support of the DC load and power will be the production and use of. In the future, can achieve micro grid and distribution network to coexist, $\mathrm{AC}$ and DC micro grid coexist, the different nature of the load according to their own needs to independently choose the first power supply the most ideal, and in the event of failure can be automatically switched to other power supply. Therefore, the research of DC micro grid, both for the improvement of the traditional power form, or for the new power supply mode into DC power supply, has a practical significance of special.

\section{REFERENCES}

[1] Z.X.Lu, C.X.Wang,and Y.He,"Review on the research of micro grid," Aut.Elec.Pow.Syst, vol.19 .pp.104-111.May 2007

[2] BEGOVI M and PREGELJ A, " Impact of renewable distributed generation on power systems ", Jou. Elec. Sci. Tech, vol. 9, pp. 654-663,July,2001

[3] LASSETER R, " The role of distributed energy resources in future electric power systems " High .Vol.Tech, vol.15, pp. 142-146,May 2009.

[4] M.Ding and Y.Y.Zhang, " The key technology in the research of micro network, " Grid technology, vol.33, pp. 6-11,June 2009

[5] Y.N.Chi, Q.Y.Li, and Y.Li, "Other large-scale wind power and grid power system operation and stability problems caused, " Elec.Equ, vol.8 pp. 16-19,October,2008

[6] Marnay C," S.Shape of the microgrid, " Pow.Engi.Soc.Wint. Meet, vol.7, pp.78-82,June 2007

[7] J.Shi, and Q.Ai, " DC micro grid modeling and stability analysis," Ele.Pow.Auto.Equip, vol.2, pp.86-90,May 2010

[8] L.Chen, X.Z.Xia, and M.F.Zhong, "Large wind turbine technology trends,"Ren.Ene,vol.17, pp.116-120,May 2003

[9] P.Li and L.Zhang, " Micro grid technology application and analysis, " Aut.Ele.Pow.Syst, vol.33, pp.109-115,May 2009.

[10] Z.H.Jing and Q.Ai , " Present situation of research on Microgrid and its application prospects in China, " Grid technology, vol.39, pp.27-31,July 2008. 